\title{
Pemanfaatan spesimen herbarium sebagai media pembelajaran bagi Guru-Guru IPA/Biologi di Kabupaten Enrekang
}

\author{
Syamsiah ${ }^{1}$, Nurhayati B. ${ }^{2}$, St. Fatmah Hiola ${ }^{3}$ \\ ${ }_{1,2,3}$ Fakultas MIPA, Universitas Negeri Makassar
}

\begin{abstract}
Plant diversity is really important to be a good learning media for students to achieve their goals. Presenting objects directly in cla ss is not easy, therefore herbarium specimens are an alternative. The purpose of Program Kemitraan Masyarakat (PKM) is to provide groups of MGMP/ Biology MGMP with understanding and skills in utilizing herbarium specimens as learning media in the classroom. This activities are carried out by lecture, demonstration and question and a nswer method. The lecture was conducted to explain basic knowle dge a bout the herbarium, and its benefits as a media. The demonstration method was carried out by the instructors to demonst rate how to make a herbarium start from plant selection to pressing. Question and answer method if there is material that is not yet clear. The training on making herbarium as a medium that is use d in cla ssroom for Science/Biology teachers group in Enrekang is going well and smoothly; 2) Science / Biology teacher groups as trainees can understand the material well and a re skilled in making herbariums starting from the sampling of plants, preservation with a lcohol, pressing, drying, until a ttaching.
\end{abstract}

Key words: training, herbarium specimens, learning media, Enrekang Regency

\section{PENDAHULUAN}

Perkembangan mutu pendidikan saat ini menjadi sorotan yang cukup tajam, utamanya pada rendahnya mutu pendidikan di Indonesia pada umumnya dan di Kabupaten Enrekang pada khususnya, banyak pihak yang mengingatkan peranan guru yang begitu sentral dalam peningkatan mutu pendidikan. Hal ini didasari pemikiran bahwa titik berat pembangunan pendidikan diletakkan pada peningkatan mutu setiap jenjang dan jenis pendidikan serta perluasan kesempatan belajar pada jenjang pendidikan menengah dalam rangka persiapan perluasan wajib belajar. Dari berbagai sorotan tersebut profesionalisme guru masih perlu dikembangkan atau dengan kata lain kinerja guru dituntut maksimal.

Pengembangan sumber daya manusia bagi guru/pendidik, khususnya pengembangan profesional guru, merupakan usaha mempersiapkan guru agar memiliki berbagai wawasan, pengetahuan, keterampilan, dan memberikan rasa percaya diri untuk melaksanakan tugas dan kewajibannya sebagai petugas profesional. Pengembangan atau peningkatan kemampuan profesional harus berdasarkan pada pada kebutuhan atau permasalahan nyata yang dihadapi oleh guru di dalam proses pembelajaran baik di dalam kelas, maupun dengan memanfaatkan lingkungan sekitarnya.

Seiring dengan fenomena tersebut di atas, pembangunan pendidikan yang lebih berkualitas telah dilaksanakan melalui berbagai upaya seperti, pengembangan dan perbaikan kurikulum, pemenuhan sarana dan prasarana pendidikan, sistem evaluasi, pengembangan bahan ajar, pelatihan guru dan tenaga pendidik, dan usaha lainnya. Namun dalam kenyataannya upaya itu belum membawa dampak yang maksimal, termasuk dalam hal belum berhasil meningkatkan profesionalisme guru, hal ini membawa dampak belum meningkatnya prestasi siswa.

Berkaitan dengan peran guru tersebut, maka forum pertemuan guru di kelompok Musyawarah Guru Mata Pelajaran (MGMP) merupakan kelompok yang sangat strategis untuk peningkatan kompetensi guru dan kinerja guru, maka pemberdayaan MGMP merupakan hal mendesak yang harus segera dilakukan. Peningkatan kemampuan guru dalam pelaksanaan proses belajar mengajar merupakan bagian dari usaha peningkatan mutu pendidikan. Salah satu bentuk 
peningkatan kemampuan guru utamanya dalam peningkatan life skill yaitu melalui berbagai kegiatan pelatihan. Salah satunya adalah pelatihan pembuatan herbarium.

Herbarium adalah tumbuhan kering yang melalui beberapa tahapan proses pengawetan, dipres dan ditempelkan pada karton manila atau sejenisnya yang dilengkapi dengan label/etiket yang berisi data terinci dari tumbuhan bersangkutan. Herbarium penting dimanfaatkan sebagai bahan studi bagi siswa dan dapat digunakan guru sebagai media/alat bantu dalam pembelajaran. Namun masih sebagian guru belum terampil membuat herbarium yang baik dan sesuai standar internasional yang telah disepakati.

Berdasarkan permasalahan yang dialami oleh kelompok MGMP SMP/SMA tersebut, maka masalah prioritas yang perlu ditangani oleh tim pengabdian kepada masyarakat bersama kelompok MGMP adalah pemanfaatan awetan tumbuhan (herbarium) sebagai media pembelajaran objek langsung.

\section{METODE PELAKSANAAN}

\section{A. Metode Survei}

Metode survei digunakan untuk mengetahui kondisi di lapangan yang akan dikaji terutama pengetahuan dasar yang dimiliki guru-guru sebagai Kelompok MGMP IPA/Biologi dalam pembuatan herbarium dan manfaatnya dalam pembelajaran di kelas. Metode ini juga digunakan untuk mempersiapkan peserta dalam rangka penentuan kondisi peserta.

\section{B. Metode Ceramah}

Metode ceramah digunakan untuk menyampaikan informasi singkat mengenai herbarium atau awetan spesies tumbuhan, mengapa harus diawetkan dan bagaimana manfaatnya di dalam proses pembelajaran di sekolah. Hal ini dimaksudkan agar peserta memiliki dasar-dasar ilmiah yag kuat dalam membuat herbarium terutama untuk jenisjenis tumbuhan yang sulit dihadirkan dalam pembelajaran di kelas.

\section{Metode Demonstrasi}

Metode ini dimanfaatkan oleh nara sumber untuk mendemonstrasikan cara-cara pembuatan herbarium (awetan tumbuhan), dan guru-guru sebagai peserta memperhatikan secara seksama untuk kemudian akan diikuti hal yang sama dalam kelompok masing-masing.

\section{Metode Diskusi}

Kegiatan diskusi dilakukan dengan tujuan agar berbagai persoalan yang ditemukan selama pelatihan berlangsung akan dibahas bersama. Melalui kegiatan ini diharapkan akan diperoleh solusi yang tepat.

Kegiatan yang dilakukan berdasarkan solusi untuk menangani permasalahan Kelompok Mitra adalah sebagai berikut:

1. Kelompok MGMP diberikan pengetahuan dasar tentang cara-cara pembuatan herbarium, dimulai dari pengambilan spesimen tumbuhan sampai pada penempelan.

2. Kelompok MGMP diberikan pelatihan tentang cara pembuatan herbarium kering.

3. Kelompok MGMP diberikan pelatihan tentang cara pembuatan herbarium basah.

4. Kelompok MGMP diberikan pengetahun dasar tentang manfaat herbarium sebagai media pembelajaran di dalam kelas.

5. Kelompok MGMP diberikan pemahaman bagaimana cara penyimpanan herbarium.

\section{HASIL DAN PEMBAHASAN}

Program Kegiatan Masyarakat (PKM) pembuatan herbarium untuk guru-guru IPA/Biologi di Kabupaten Enrekang, merupakan salah satu kegiatan dalam pengabdian kepada masyarakat yang dilakukan kepada kelompok MGMP di Kabupaten Enrekang. Kegiatan ini dilakukan dalam bentuk pelatihan dengan melibatkan guruguru baik di tingkat SLTP (guru IPA) maupun di tingkat SLTA (guru Biologi). 


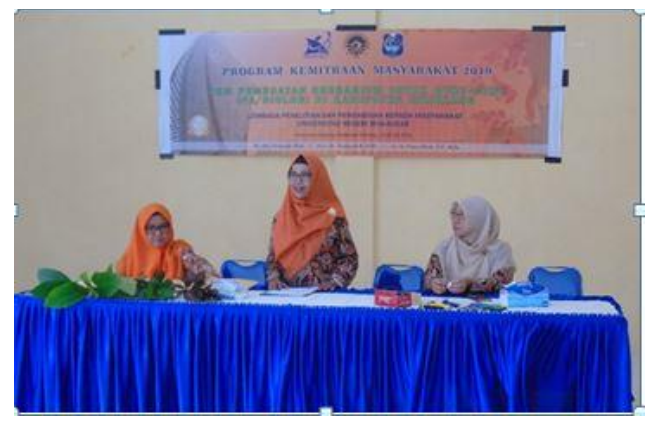

Gambar 1. Pembukaan pelatihan bagi Guru IPA/Biologi

Herbarium merupakan suatu spesimen dari bahan tumbuhan yang telah dimatikan dan diawetkan melalui metode tertentu. Spesimen herbarium yang baik harusnya memberikan informasi yang lengkap yang ada pada tumbuhan yang bersangkutan, dengan kata lain koleksi herbarium harus mengandung semua bagian tumbuhan (Vogel, 1987). Herbarium biasanya dilengkapi dengan data-data mengenai tumbuhan yang diawetkan, baik data morfologi, ekologi, maupun geografi. Selain itu herbarium juga memuat waktu dan tempat mengoleksi, serta nama pengkoleksi. Pembuatan awetan spesimen diperlukan untuk tujuan pengamatan spesimen secara praktis tanpa harus mencari bahan segar yang baru. Terutama untuk spesimen-spesimen yang sulit ditemukan di alam.

Agar suatu tumbuhan dapat terus dilihat keberadaannya, maka pengawetan tumbuhan menjadi alternatif untuk melindungi keberadaan tumbuhan, dan salah satu pengawetan tumbuhan adalah herbarium (Widhy, 2012). Herbarium merupakan suatu spesimen dari bahan tumbuhan yang telah dimatikan dan diawetkan melalui metode tertentu. Dua metode yang digunakan dalam membuat spesimen herbarium, yaitu pengeringan langsung di lapangan dan pengawetan dalam alkohol beberapa lama sebelum dikeringkan (Vogel, 1987). Selanjutnya dikatakan bahwa spesimen herbarium yang ideal adalah spesimen yang memuat baian tumbuhan seperti akar, batang, daun, bunga, dan buah, tetapi cabang/ranting dengan daun dan bunga atau buah adalah hal yang sangat penting untuk suatu tujuan identifikasi.

Enrekang adalah salah satu kabupaten di Sulawesi Selatan yang memiliki sumber daya alam hayati khususnya tumbuhan yang beranekaragam (BPS Enrekang, 2017). Keanekaragaman hayati merupakan aset yang tidak ternilai untuk dapat dimanfaatkan dengan sebaik-baiknya dalam ilmu pengetahuan. Kenanekaragaman hayati merupakan salah satu kompetensi dasar (KD) dengan segala indikator dan tujuan pembelajaran yang harus dicapai peserta didik dalam pembelajarannya.

Keanekaragaman tumbuhan sangatlah penting menjadi media pembelajaran yang baik bagi peserta didik untuk dapat mencapai tujuan pembelajarannya. Usaha memaksimalkan hasil belajar peserta didik sangat baik jika menggunakan objek langsung sebagai alat bantu (media) pembelajaran, tetapi di balik itu dibutuhkan waktu yang tidak sedikit dalam proses belajar-mengajar. Oleh karena itu diperlukan objek tumbuhan dihadirkan di dalam kelas tetapi dalam persi lain yaitu melalui awetan tumbuhan (herbarium) sebagai media pembelajaran.

Untuk seorang peneliti, eksplorasi terhadap tumbuh-tumbuhan merupakan salah satu kegiatan yang dilakukan dengan tujuan untuk memperoleh data sebanyak-banyaknya tentang sumberdaya hayati. Hasil eksplorasi dilengkapi dengan pengambilan spesimen dan pencandraan terhadap ciriciri yang dimiliki dan kemudian dilakukan pengawetan maupun pengkoleksian. Spesimen dan data yang telah diperoleh kemudian dikumpulkan dan diolah sebagai herbarium untuk dijadikan sumber informasi dalam pengelolaan sumberdaya hayati, maupun untuk keperluan proses pembelajaran.

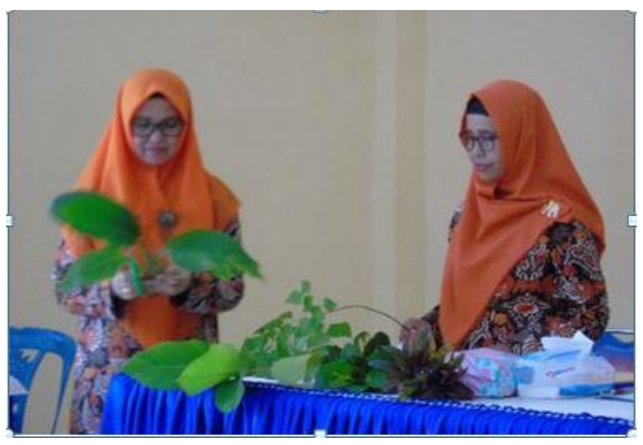

Gambar 2. Ketua Tim PKM menjelaskan cara pemilihan objek tumbuhan 


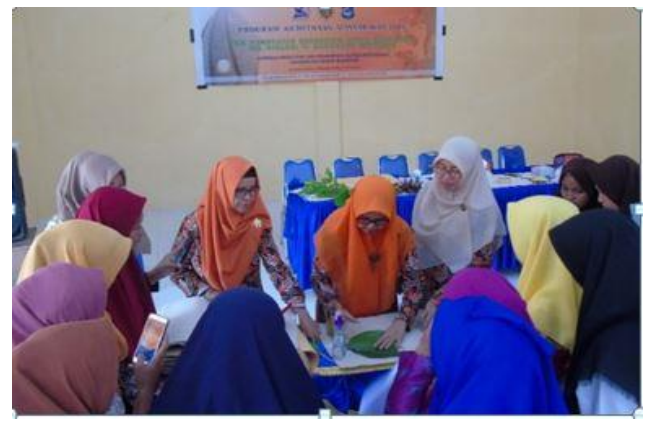

Gambar 3. Ketua Tim PKM mendemontrasikan cara pembuatan herbarium

Spesimen herbarium sangat penting artinya sebagai koleksi untuk kepentingan penelitian dan identifikasi, dan pembelajaran. Lebih jelasnya beberapa fungsi spesimen herbarium antar lain: 1) bahan peraga pelajaran botani; 2) bahan penelitian; 3) alat pembantu identifikasi tumbuhan; 4) bukti keanekaragaman; 5) spesimen acuan untuk publikasi spesies baru; 6) pusat referensi; 7) lembaga dokumentasi; dan 8) sebagai pusat penyimpanan data.

Pengaplikasian spesimen herbarium yaitu dapat langsung di bawah ke dalam kelas sebagai media pembelajaran atau laboratorium sebagai bahan pelengkap praktikum. Dengan membawa spesimen herbarium di kelas peserta didik dapat dengan mudah mempelajari dan mengidentifikasi spesimen tertentu.

Guru-guru IPA/Biologi sebagai peserta pelatihan yang ikut dalam kegiatan ini sangat antusias terbukti dengan jumlah peserta, hadir tepat waktu dan mereka nampak aktif dalam diskusi, praktek pembuatan herbarium, dan beberapa peserta mengajukan pertanyaan.

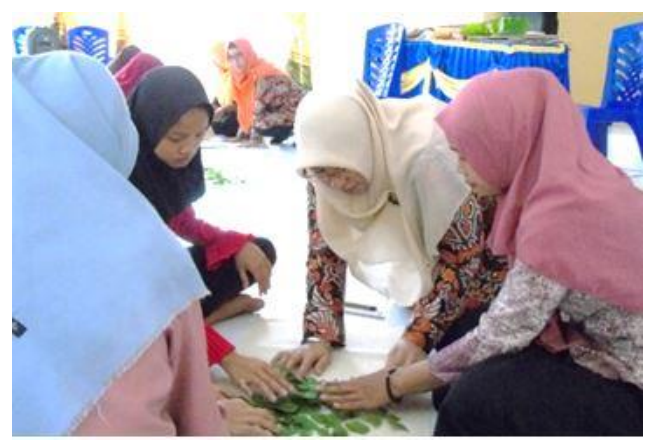

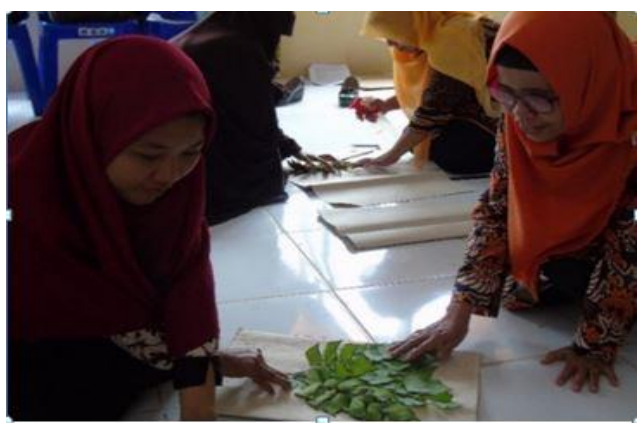

Gambar 4. Kegiatan menempel herbarium oleh masing-masing kelompok

Kegiatan pelatihan yang diawali dengan metode ceramah, terlihat sebagian besar peserta sudah paham, selanjutnya ketua Tim PKM sebagai narasumber/instruktur mendemontrasikan cara-cara koleksi tumbuhan mulai dari pengambilan tumbuhan sampai pada pengepresan, kemudian langsung dilatihkan kepada peserta yang sebelumnnya telah didistribusi dalam empat kelompok.

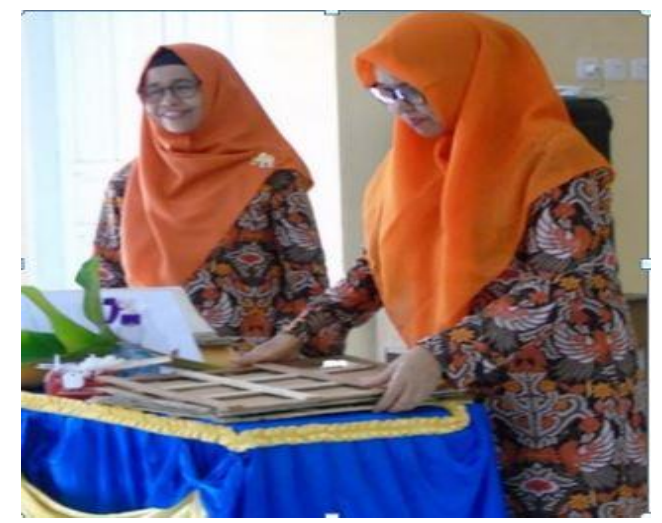

Gambar 5. Pengepresan spesimen menggunakan sasak

Sesi tanya jawab dilaksanakan di akhir kegiatan pelatihan dan terungkap beberapa kendala dan keterbatasan kelompok MGMP IPA/Biologi, terutama dalam proses penyimpanan specimen supaya terhindar dari hama dan fungi.

Hasil evaluasi kegiatan, yang dimulai dari pemberian materi sampai pada saat praktik menunjukkan kegiatan berjalan sangat lancar, hal ini tidak lain merupakan hasil kerjasama antara tim pelaksana PKM dengan kelompok MGMP IPA/Biologi sebagai mitra. Peserta sangat antusias dan cepat menyerap materi yang diberikan. 


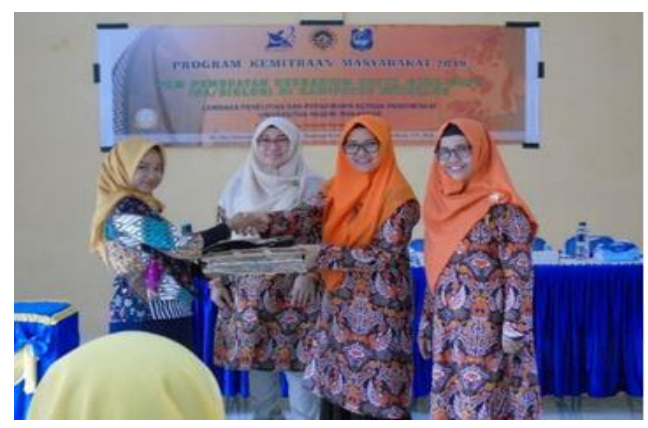

Gambar 6. Penyerahan perangkat herbarium kepada ketua kelompok

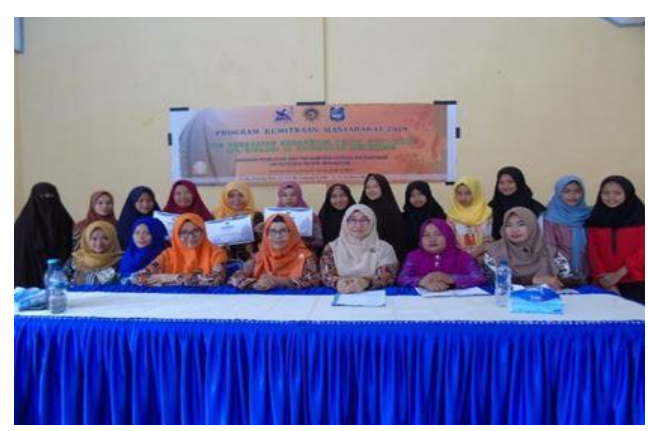

Gambar 7. Foto bersama Tim PKM dan peserta

\section{KESIMPULAN}

a. Kegiatan pelatihan pembuatan herbarium sebagai media yang dimanfaatkan dalam pembelajaran di kelas pada Kelompok guru IPA/Biologi di Kabupaten Enrekang berjalan dengan baik dan lancar. b. Kelompok guru IPA/Biologi sebagai peserta pelatihan dapat memahami materi dengan baik dan terampil dalam pembuatan herbarium yang dimulai dari pemilihan dan pengambilan sampel tumbuhan, pengawetan dengan alkohol, pengeringan, sampai pada penempelan.

\section{UCAPAN TERIMA KASIH}

Kegiatan pengabdian kepada masyarakat dengan judul PKM Pembuatan Herbarium untuk Guru-guru IPA/Biologi di Kabupaten Enrekang, terlaksana dengan baik berkat bantuan dan dukungan dari berbagai pihak, oleh karena itu Tim pelaksana PKM mengucapkan terima kasih kepada Universitas Negeri Makassar atas bantuan dana (PNBP-FMIPA), LP2M UNM dan Kelompok MGMP di Kabupaten Enrekang sebagai mitra.

\section{DAFTAR PUSTAKA}

Badan Pusat Statistika Enrekang. 2017. Pusat Data Statistika Kabupaten Enrekang

Vogel de, E. F. 1987 Manual of Herbarium Taxonomy, Theory and Practice. Unesco

Widhy P. H, 2012, Herbarium. Diakses 4 Oktober 2019. 